\title{
Correction to: Effect of closure of live poultry markets in China on prevention and control of human infection with H7N9 avian influenza: a case study of four cities in Jiangsu Province
}

\author{
Junru Ma ${ }^{1}$. Nichao Yang ${ }^{1} \cdot$ Hai Gu${ }^{1} \cdot$ Lan Bai ${ }^{1} \cdot$ Jun Sun ${ }^{1} \cdot$ Shuyan Gu${ }^{1}$. \\ Jinghong $\mathrm{Gu}^{2}$
}

Published online: 11 December 2019

(c) Springer Nature Limited 2019

\section{Correction to: Journal of Public Health Policy https://doi.org/10.1057/s41271-019-00185-2}

Due to an unfortunate oversight, the acknowledgements has been omitted:

This article is the result of a project-Jiangsu Provincial Major Science \& Technology Demonstration Project (No. BE2017749). And we are grateful to the Jiangsu Provincial Center For Disease Control And Prevention for providing data and financial support.

The authors apologise for this mistake.

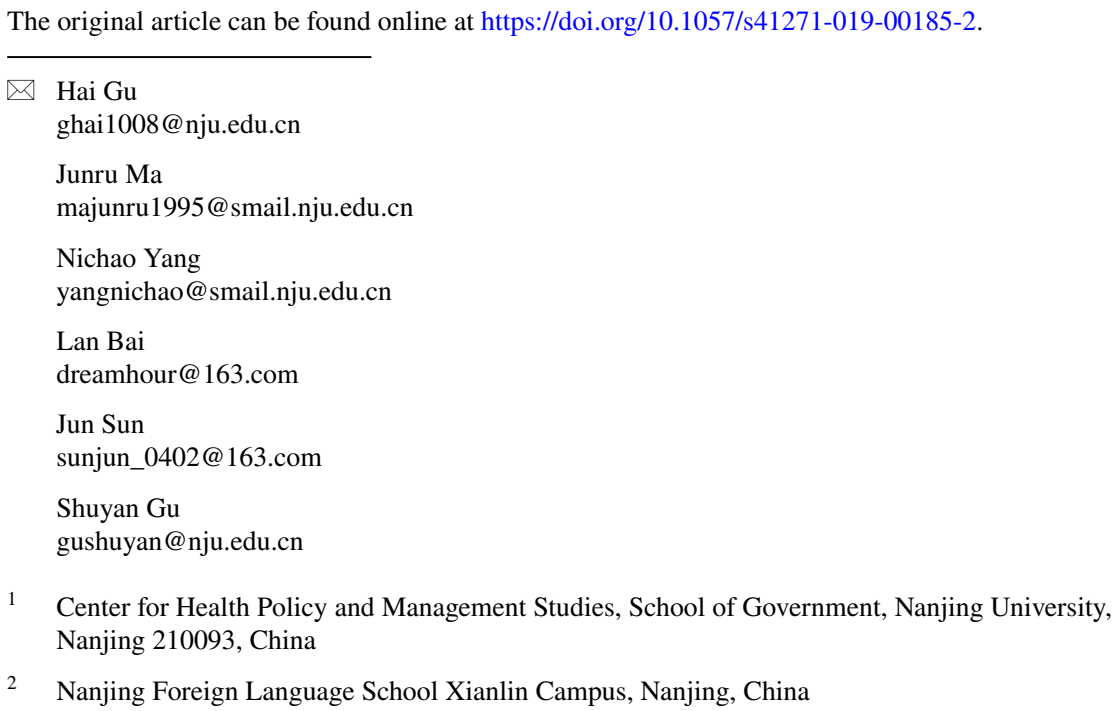

Hai Gu

ghai1008@nju.edu.cn

Junru Ma

majunru1995@smail.nju.edu.cn

Nichao Yang

yangnichao@smail.nju.edu.cn

Lan Bai

dreamhour@163.com

Jun Sun

sunjun_0402@163.com

Shuyan Gu

gushuyan@nju.edu.cn

1 Center for Health Policy and Management Studies, School of Government, Nanjing University, Nanjing 210093, China

2 Nanjing Foreign Language School Xianlin Campus, Nanjing, China 
Publisher's Note Springer Nature remains neutral with regard to jurisdictional claims in published maps and institutional affiliations. 